\title{
Matéria seca em raízes de mandioca determinada pelos métodos da balança hidrostática e de secagem em estufa
}

\author{
Augusto Carlos Pola, Eduardo da Costa Nunes e Alexsander Luis Moreto
}

\begin{abstract}
Resumo - Objetivou-se neste estudo comparar duas diferentes metodologias para a determinação da matéria seca em raízes de mandioca. Para tal, foram utilizadas raízes de quatro cultivares, colhidas de 10 a 22 meses após o plantio, em Jaguaruna, SC. Em um segundo ensaio, raízes do cultivar Sambaqui foram colhidas mensalmente em duas lavouras com tipos distintos de solo. No primeiro ensaio, o método da secagem apresentou um teor médio de matéria seca 5,3\% inferior ao da balança hidrostática no primeiro ciclo vegetativo (estádio de dormência). No segundo ciclo vegetativo o método de secagem apresentou teores médios de $5,7 \%$ e $6,7 \%$ superiores aos da balança hidrostática para os cultivares Sambaqui e Luna, respectivamente. Os cultivares Mandim Branca e Olho Junto não apresentaram diferenças significativas $(p>0,05)$ entre os métodos no segundo ciclo vegetativo. No segundo ensaio, com o cultivar Sambaqui, o método de secagem também apresentou, no segundo ciclo vegetativo, um teor médio de matéria seca 6,0\% superior ao obtido com o método gravimétrico. As diferenças nos teores de matéria seca entre os métodos variaram de acordo com o genótipo, época de colheita e tipo de solo.
\end{abstract}

Termos para indexação: Manihot esculenta Crantz; gravidade específica; épocas de colheita.

\section{Dry matter in cassava roots determined by the hydrostatic balance and oven-dry methods}

Abstract - The objective of this study was to evaluate two different methodologies for the determination of dry matter in cassava roots. For this purpose, in the first trial, roots of four cultivars were used, harvested 10 to 22 months after planting. In a second trial, roots of the cultivar Sambaqui were harvested monthly from two crops with different types of soil. Data of the different cultivars showed that the drying method presented an average dry matter content $5.3 \%$ lower than that of the hydrostatic balance in the first vegetative cycle (dormancy stage). In the second vegetative cycle, the drying method presented average levels of $5.7 \%$ and $6.7 \%$ higher than the hydrostatic balance for the cultivars Sambaqui and Luna, respectively. The cultivars Mandim Branca and Olho Junto showed no significant differences $(p>0.05)$ between the methods in the second vegetative cycle. In the second test, with the cultivar Sambaqui, the drying method also presented, in the second vegetative cycle, an average dry matter content $6.0 \%$ higher than that obtained with the gravimetric method. Differences in dry matter content between methods varied according to genotype, harvest time and soil type.

Index Terms: Manihot esculenta Crantz; specific gravity; harvest times.

\section{Introdução}

Dentre muitas características desejáveis, os cultivares de mandioca destinadas às indústrias de farinha e fécula devem apresentar elevada produtividade e altos teores de matéria seca (MS) nas raízes tuberosas. De maneira geral, estes teores variam de 17 a $47 \%$, com maior concentração entre 20 e $40 \%$ (POLA et al., 2017), sendo esta variação dependente do cultivar, das condições climáticas durante o ciclo de produção, do tipo de solo, da ocorrência de pragas e doenças, do sistema de cultivo (tratos culturais) e da época de colheita, dentre outros fatores.

As colheitas do litoral sul de Santa Catarina ocorrem, principalmente, de junho a agosto, em torno de 9 a 11 meses após o plantio (MAP), quando as folhas caem devido à dormência das plantas. Quando a lavoura permanece por mais um ciclo vegetativo, geralmente elas são colhidas nos meses de abril a junho (de 19 a 21 MAP). O conhecimento do teor de matéria seca das raízes é importante para a mandiocultura, principalmente em razão desta característica estar diretamente relacionada com o rendimento de farinha e fécula. Além disso, este conhecimento auxilia na definição dos preços que serão pagos ao agricultor pelas raízes, sendo também um parâmetro importante na definição dos momentos de iniciar e/ou paralisar a colheita, permitindo um melhor planejamento e a otimização da capacidade industrial.

O método mais utilizado pelas fecularias para determinar o teor de matéria seca das raízes de mandioca é o da gravidade específica, também chamado de método da balança hidrostática (CEREDA et al., 2003), uma vez que é relativamente simples e rápido. No Brasil é muito utilizada uma equação linear simples

Recebido em 15/10/2019. Aceito para publicação em 13/4/2020.

Engenheiro-agrônomo, MSc., Epagri/Estação Experimental de Urussanga, Rodovia SC 108, km 353 No 1563, Bairro da Estação, 88.840-000, Urussanga, SC, Fone: (48)34031384, e-mail: pola@epagri.sc.gov.br.

Engenheiro-agrônomo, Dr., Epagri/Estação Experimental de Urussanga, e-mail: alexsandermoreto@epagri.sc.gov.br, eduardon@epagri.sc.gov.br. 
obtida por Grossman \& Freitas (1950), a qual permite estimar a matéria seca a partir do peso de 3,0kg de raízes submersas em água.

Com o objetivo de avaliar as diferenças entre a matéria seca obtida pelo método da balança hidrostática e a obtida pelo método de secagem em estufa, foram realizadas avaliações mensais em quatro cultivares de mandioca no período de 10 a 22 MAP.

\section{Material e métodos}

Neste estudo foram realizados dois ensaios. O primeiro foi instalado em meados de setembro de 2015 em um Neossolo quartzarênico no município de Jaguaruna, SC. O ensaio foi composto por 13 experimentos (13 épocas de colheita), cada um com delineamento experimental de blocos ao acaso com quatro repetições, quatro tratamentos (cultivares) e parcelas de 4 linhas com 7 plantas por linha. Cada experimento foi colhido mensalmente no dia 15 de cada mês, de julho de 2016 a julho de 2017 (10 a 22 MAP). Nas avaliações foram utilizadas as 10 plantas centrais, de cujas raízes foi retirada uma amostra de $3,0 \mathrm{~kg}$. O espaçamento utilizado foi de $0,80 \times 0,80 \mathrm{~m}$. Os cultivares avaliados foram Mandim Branca, Olho Junto, Sambaqui e Luna.

O segundo ensaio consistiu de amostragens mensais de raízes em duas lavouras do cultivar Sambaqui localizadas em Jaguaruna e Sangão, SC, em Neossolo quartzarênico e Argissolo, respectivamente. A distância entre as lavouras é de aproximadamente $12 \mathrm{~km}$. O plantio das lavouras ocorreu em meados de setembro e o espaçamento utilizado em Jaguaruna foi de 0,8 x 0,8m e em Sangão de $1,0 \times 0,8 \mathrm{~m}$. Foram coletadas mensalmente, no dia 15 de cada mês, em cada lavoura, cinco amostras de $3,0 \mathrm{~kg}$ retiradas de plantas localizadas em cinco pontos escolhidos aleatoriamente na área e determinados os teores de matéria seca pelos dois métodos acima descritos.

O clima da região do estudo é Cfa. Ambos os municípios apresentam uma temperatura média anual de $19,1^{\circ} \mathrm{C}$, média das máximas de $24,0^{\circ} \mathrm{C}$ e média das mínimas de $15,0^{\circ} \mathrm{C}$. A precipi- tação total anual média da região é de 1450mm (WREGE et al., 2012).

$\mathrm{Na}$ determinação de matéria seca pelo método da balança hidrostática as amostras de 3,0kg foram pesadas dentro d'água, sendo o teor de matéria seca (MS) calculado através da equação obtida por Grossman \& Freitas (1950), como segue:

\section{$M S=15,75+0,0564 P$}

onde $\mathrm{P}=$ peso de $3,0 \mathrm{~kg}$ de raízes submersas em água. As raízes que eventualmente boiavam na água foram substituídas.

Para a determinação de MS pelo método de secagem em estufa, foram retirados 500 gramas de tolete da polpa, do terço médio das raízes das amostras de $3,0 \mathrm{~kg}$, que foram triturados em liquidificador industrial com um volume de água de 2,5 litros. Após este processo, a massa obtida foi submetida a um processo de filtração com prensagem em tecido tipo "voil", separando-se, após cinco lavagens sucessivas, o amido que ficou disperso na água de lavagem e o resíduo que ficou retido no tecido. 0 amido foi separado do líquido sobrenadante após 24 horas de decantação. Este amido e o resíduo foram pesados e colocados a secar em estufa até peso constante. A determinação da MS foi realizada através da seguinte equação: $M S=(A+R) / 5$, onde $A$ e $R$ são o peso do amido e do resíduo, respectivamente, após secagem, em gramas, sendo a MS dada em porcentagem. O método acima descrito foi adaptado a partir da metodologia apresentada por Nunes (2013), tendo sido considerado como referência no presente estudo.

Foi utilizado o teste $\mathrm{F}$ para a comparação de médias $(P=0,05$ e $P=0,01)$. A significância da regressão linear foi avaliada através da aplicação do teste $t$ ao coeficiente angular da equação, aos níveis de $\mathrm{P}=0,05$ e $\mathrm{P}=0,01$.

\section{Resultados e discussão}

Foi observado em todos os cultivares que o método da balança hidrostática apresentou teores médios de matéria seca superiores ao obtido pelo método de secagem no período de julho a novembro (10 a $13 \mathrm{MAP}$ ), e teores médios inferiores ao método de secagem no período de dezembro a julho (14 a 22 MAP) (Figura 1). Oliveira et al. (2011) observaram que o teor de amido de seis clones de mandioca foi superestimado no primeiro ciclo vegetativo pelo método da balança hidrostática em relação ao amido extraído das raízes e secagem em estufa, resultados estes semelhantes aos obtidos para o primeiro ciclo no presente trabalho.

Ocorreram diferenças estatisticamente significativas entre os valores de matéria seca obtidos pelo método da estufa e pelo da balança hidrostática (Tabela 1). Estas diferenças dependeram do cultivar e do estádio fenológico, como pode ser verificado na Figura 1 e na Tabela 1. Nesta tabela é possível verificar que na fase de 10 a 13 MAP a diferença média entre os valores de MS entre os dois métodos é de aproximadamente 5,3\%, com diferenças máximas obtidas de 7,3 a 9,2\%.

Como pode ser observado na Figura 1, a partir de novembro (14 a $22 \mathrm{MAP}$ ) o método da balança hidrostática passou a apresentar menores teores de matéria seca que o de secagem em estufa. Nas amostras dos cultivares Mandim Branca e Olho Junto não foram observadas diferenças estatisticamente significativas ( $p>0,05)$ entre os valores de matéria seca obtidos pelos dois métodos (Tabela 1). Entretanto, ocorreram diferenças médias significativas $(p<0,01)$ entre os valores de matéria seca dos cultivares Sambaqui e Luna $(5,7 \%$ e $6,7 \%$, respectivamente), os quais apresentaram diferenças máximas superiores a $10 \%$.

Na Tabela 2 são apresentados os parâmetros da regressão linear entre a matéria seca das raízes obtida por secagem em estufa e o correspondente peso das amostras de $3,0 \mathrm{~kg}$ em água, para os ciclos de produção anual (10 a 13 MAP) e bianual (14 a 22 MAP). Na fase de 10 a 13 MAP nenhum cultivar apresentou uma relação linear significativa (Tabela 2), e seus coeficientes de determinação ficaram próximos de zero. Individualmente, estas quatro equações não permitem estimar a matéria seca a partir do peso das raízes em água, em razão da sua não significância estatística. Entretanto, o conjunto dos dados obtidos revelou uma relação linear com significância $(p<0,01)$ para o citado período fenológico (10 a $13 \mathrm{MAP}$ ), como pode 


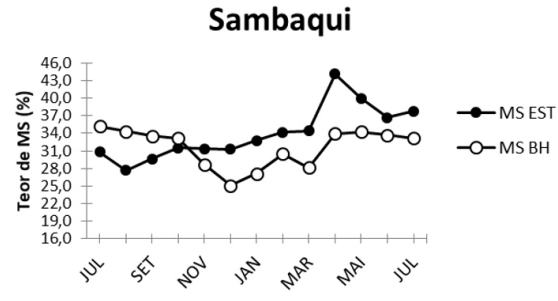

Luna

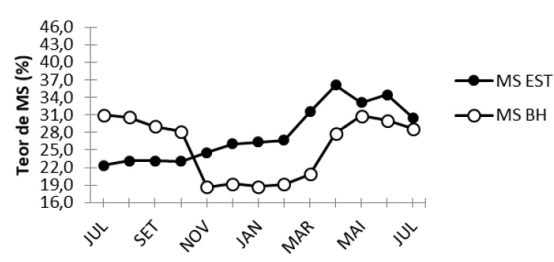

Figura 1. Porcentagem de matéria seca (MS), em raízes tuberosas de mandioca, determinada mensalmente pelo método da secagem em estufa (MS EST) e pelo método da balança hidrostática (MS BH) dos cultivares Sambaqui, Mandim Branca, Luna e Olho Junto colhidos no período de julho de 2016 a julho de 2017 (10 a 22 meses após o plantio) em Jaguaruna, SC. Cada ponto representa a média de três determinações Figure 1. Percentage of dry matter (DM) in cassava tuberous roots, determined monthly by the oven drying method (MS EST) and the hydrostatic balance method (MS BH) of the cultivars Sambaqui, Mandim Branca, Luna and Olho Junto harvested from July 2016 to July 2017 (10 to 22 months after planting) in Jaguaruna, SC. Each point represents the average of three determinations

Tabela 1. Diferença média e máxima observadas entre o teor (\%) de matéria seca de raízes tuberosas de mandioca determinadas por secagem em estufa (EST) e pelo método da balança hidrostática $(\mathrm{BH})$, de quatro cultivares, no período fenológico de julho a outubro de 2016 (10 a13 meses MAP) e de novembro de 2016 a julho de 2017 (14 a 22 MAP), em Jaguaruna, SC

Table 1. Average and maximum difference observed between the dry matter content (\%) of cassava tuberous roots determined by oven drying method (EST) and the hydrostatic balance method (BH) of four cultivars in the period of July to October 2016 (10 to 13 months MAP) and from November 2016 to July 2017 (14 to 22 MAP), in Jaguaruna, SC, Brazil

\begin{tabular}{|c|c|c|c|c|c|}
\hline \multirow[b]{2}{*}{ Cultivares } & \multicolumn{2}{|c|}{10 a 13 MAP } & \multicolumn{2}{|c|}{14 a 22 MAP } & \multirow{2}{*}{$\begin{array}{c}10 \text { a } 22 \\
\text { MAP } \\
\text { Matéria } \\
\text { Seca } \\
\text { (EST) }\end{array}$} \\
\hline & $\begin{array}{c}\text { Diferença } \\
\text { média } \\
\text { (EST - BH) }\end{array}$ & $\begin{array}{l}\text { Diferença } \\
\text { Máxima } \\
\text { (EST - BH) }\end{array}$ & $\begin{array}{c}\text { Diferença } \\
\text { média } \\
\text { (EST - BH) }\end{array}$ & $\begin{array}{c}\text { Diferença } \\
\text { Máxima } \\
\text { (EST - BH) }\end{array}$ & \\
\hline Sambaqui & $-4,07 *$ & $-7,26$ & $5,69 * *$ & 11,48 & 34,83 \\
\hline Mandim Branca & $-5,90 * *$ & $-9,17$ & $1,56^{\mathrm{NS}}$ & 7,29 & 29,64 \\
\hline Luna & $-7,09 * *$ & $-8,81$ & $6,68 * *$ & 14,88 & 28,81 \\
\hline Olho Junto & $-4,22 * *$ & $-7,73$ & $0,93^{\mathrm{NS}}$ & 2,51 & 31,11 \\
\hline Média & $-5,32$ & & 3,71 & & \\
\hline
\end{tabular}

ser observado na Figura 3 (equação MS2). Faria \& Cereda (1992), citados por Cereda et al. (2003) também observaram uma não significância estatística entre a matéria seca de raízes do culti- var IAC 12-829 determinada através de secagem em estufa e a estimada pela balança hidrostática.

Considerando uma taxa de conversão de matéria seca nas raízes para ren- dimento de farinha de 1:1, uma diferença de $5,0 \%$ na estimativa de matéria seca das raízes representaria uma diferença de $50 \mathrm{~kg}$ de farinha por tonelada de raiz beneficiada, o que equivale a uma saca de farinha. Portanto, as diferenças estatisticamente significativas que constam na Tabela 1 podem ser consideradas relativamente elevadas. Na realidade, porém, o rendimento de farinha é inferior ao teor de matéria seca das raízes devido a fatores como a separação da película e das pontas quebradas da raiz, a peneiragem, a umidade da farinha, o tipo de farinha e aqueles relacionados ao rendimento de engenho como um todo. Aristizábal et al. (2017) apresentaram um esquema do balanço de massa da produção de farinha de mandioca onde raízes lavadas com 35,0\% de matéria seca proporcionaram um rendimento de $28,0 \%$ de farinha refinada.

Os resultados do segundo ensaio, em que raízes do cultivar Sambaqui foram coletados em duas lavouras com diferentes tipos de solo, são apresentados na Figura 2. É possível observar nesta figura que em ambos os locais a balança hidrostática apresentou valores superiores de matéria seca com relação aos obtidos com o método da secagem nos dois primeiros meses (julho e agosto), mas depois passa a apresentar valores inferiores, comportamento este semeIhante ao observado nos quatro cultivares do experimento anterior (Figura 1). Neste segundo experimento, com o cultivar Sambaqui, foram obtidos com o método gravimétrico teores médios de $4,3 \%$ e $7.8 \%$ inferiores ao método de secagem no mês de abril (19 MAP) em Jaguaruna e Sangão, respectivamente, com média de $6,0 \%$ para este mês, quando geralmente são iniciadas as colheitas das lavouras de dois ciclos de produção (bianual).

É possível que os teores inferiores obtidos com o método da balança hidrostática nos dois experimentos estejam associados à brotação (rebrote) do segundo ciclo vegetativo, quando ocorre um aporte de carboidratos das raízes para o desenvolvimento da parte aérea (caules e folhas). Foram observadas raízes que inclusive boiavam, ou seja, com densidade inferior à da água (densidade relativa menor que 1,0$)$, principalmente nas pesagens do cultivar Luna no perío- 


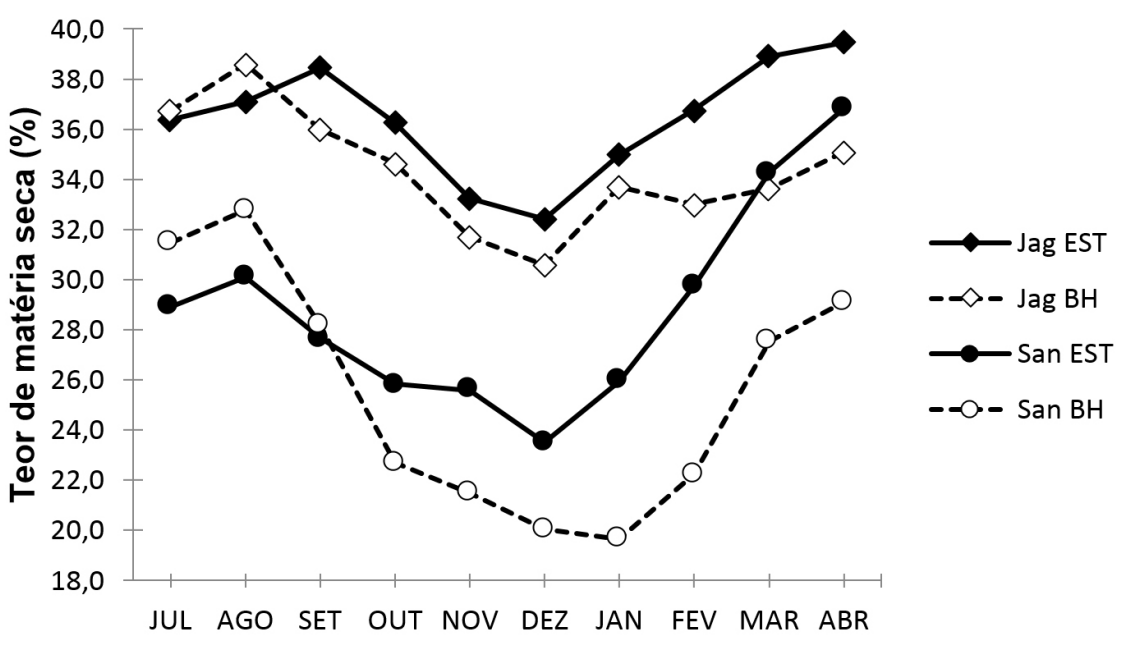

Figura 2. Teores médios de matéria seca determinada por secagem em estufa (EST) e estimada pelo método da balança hidrostática $(\mathrm{BH})$ de raízes tuberosas de mandioca Sambaqui colhidas no período de julho de 2016 a julho de 2017 (10 a 22 meses após o plantio) em Jaguaruna, SC. Cada ponto representa a média de três determinações Figure 2. Average dry matter content determined by drying in an oven (EST) and estimated by the hydrostatic balance method $(\mathrm{BH})$ of tuberous roots of cassava Sambaqui harvested from July 2016 to July 2017 (10 to 22 months after the planting) in Jaguaruna, SC. Each point represents the average of three determinations

Tabela 2. Coeficientes lineares (a) e angulares (b) das equações de regressão linear entre a matéria seca de raízes tuberosas de mandioca determinada pelo método de secagem em estufa e o peso de 3,0kg de raízes submersas em água de quatro cultivares de mandioca, com respectivos coeficientes de determinação $\left(R^{2}\right)$ e erro padrão da estimativa (Se), dos períodos de 10 a 13 meses após o plantio (MAP) e de 14 a 22 MAP. Jaguaruna, SC, julho de 2016 a julho de 2017

Table 2. Linear (a) and angular (b) coefficients of the linear regression equations between cassava root dry matter determined by the oven drying method and the weight of $3.0 \mathrm{~kg}$ of submerged roots in water of four cassava cultivars, with respective determination coefficients $\left(R^{2}\right)$ and standard error of estimation (Se), from 10 to 13 months after planting (MAP) and from 14 to 22 MAP. Jaguaruna, SC, Brazil, July 2016 to July 2017

\begin{tabular}{|c|c|c|c|c|c|c|c|c|}
\hline \multirow{3}{*}{ Cultivares } & \multicolumn{4}{|c|}{10 a 13 MAP } & \multicolumn{4}{|c|}{14 a 22 MAP } \\
\hline & \multicolumn{2}{|c|}{ Coeficientes } & \multirow{2}{*}{$\mathbf{R}^{2}$} & \multirow[t]{2}{*}{ Se } & \multicolumn{2}{|c|}{ Coeficientes } & \multirow{2}{*}{$\mathbf{R}^{2}$} & \multirow[t]{2}{*}{ Se } \\
\hline & a & b & & & a & b & & \\
\hline Sambaqui & 28,16 & $0,0057^{\mathrm{NS}}$ & 0,01 & 2,49 & 23,89 & $0,0475 * *$ & 0,61 & 2,76 \\
\hline Mandim Branca & 31,24 & $-0,0179^{N S}$ & 0,09 & 1,44 & 19,54 & $0,0473 * *$ & 0,56 & 2,58 \\
\hline Luna & 18,19 & $0,0186^{\mathrm{NS}}$ & 0,13 & 1,63 & 27,85 & $0,0226 *$ & 0,29 & 3,50 \\
\hline Olho Junto & 21,36 & $0,0228^{N S}$ & 0,10 & 1,46 & 15,35 & $0,0612 * *$ & 0,83 & 1,24 \\
\hline
\end{tabular}

$*{ }^{* *}$ : o coeficiente angular é significativamente diferente de zero, pelo teste $t$, ao nível de $5 \%$ e $1 \%$, respectivamente; NS: não significativo ao nível de $5 \%$.

do de 14 a 18 MAP (Figura 1). Maeda \& Dip (2000) observaram em seu trabalho que algumas raízes de mandioca apresentaram peso específico inferior a 1,0 e relacionam estas ocorrências com a presença de gases internos nas raízes. Sugerem que este fator seja um dos responsáveis pelo erro padrão da relação linear que obtiveram entre peso especí-

fico e porcentagem mássica de água das raízes. Bregagnoli et al. (2006) citam em seu estudo com batata que espaços internos no floema e no parênquima dos tubérculos podem ser um dos fatores que contribuem para as diferenças na matéria seca que foram obtidas com a utilização dos métodos de secagem em estufa e gravidade específica.
Na Figura 3 são apresentadas graficamente as duas equações lineares que representam a relação entre o teor de matéria seca determinado por secagem em estufa e o peso de 3,0kg de raízes na água (referentes aos períodos de 10 a 13 MAP e de 14 a 22 MAP dos quatro cultivares de mandioca avaliadas). Nesta figura é possível visualizar as retas representativas das duas equações e sua relação com a reta elaborada a partir da equação proposta por Grossman \& Freitas (1950). Estes autores elaboraram esta equação final a partir de 14 equações com coeficientes de determinação que variaram de $R^{2}=0,15$ a 0,66 e um valor médio de $R^{2}=0,38$, utilizando diversos genótipos de uma coleção de mandioca colhidos ao longo de seis anos em diferentes tipos de solo. Assim, temos que as Figuras 2 e 3 e os resultados obtidos por Grossman \& Freitas (1950) indicam que podem ocorrer variações entre os valores de matéria seca obtidos pelos dois métodos e que estas podem ser decorrentes de fatores relacionados ao genótipo, ano (clima), do tipo de solo e dos tratos culturais, dentre outros.

Carvalho et al. (2007) concluíram em seu estudo que o método de determinação da matéria seca por meio da balança hidrostática não apresentou exatidão e precisão, mas que a simplicidade e robustez do processo fazem com que seja utilizado na rotina industrial de beneficiamento da mandioca. Cereda et al. (2003) recomendam que para meIhorar a avaliação do teor de amido em função da balança hidrostática deve-se estabelecer taxas de conversão em função da variedade, do mês de colheita, da região e da idade da planta.

\section{Conclusões}

O método de secagem em estufa apresentou teores médios de matéria seca inferiores aos obtidos com o método gravimétrico no primeiro ciclo vegetativo e teores médios superiores no segundo ciclo.

A magnitude da diferença entre os 


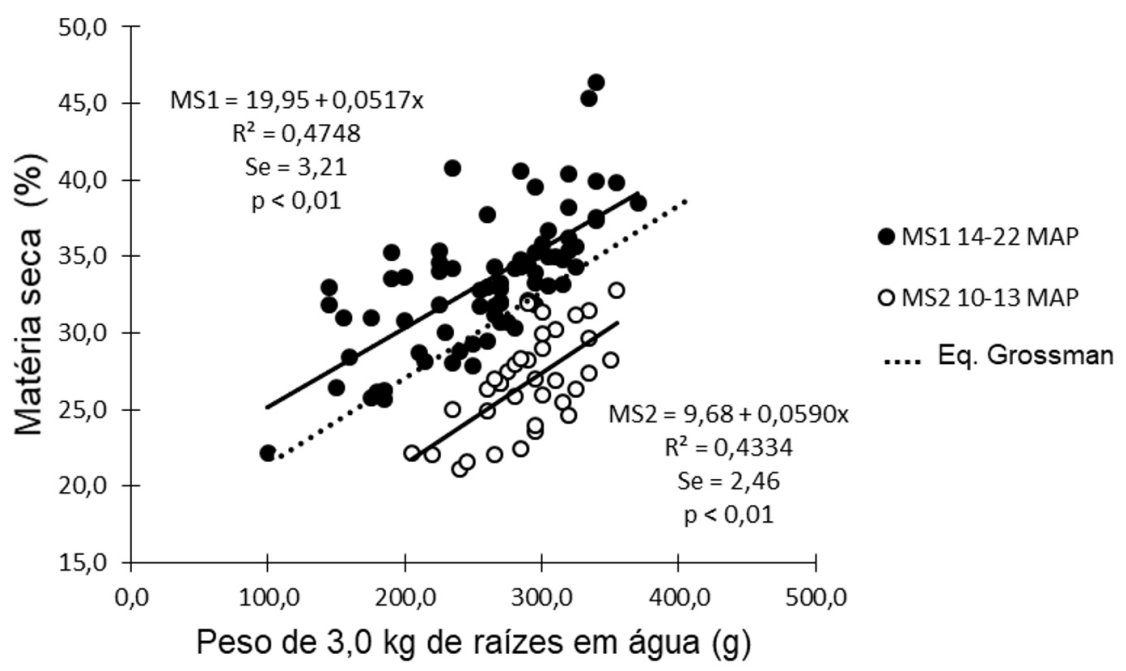

Figura 3. Equações de regressão linear simples entre o peso de 3,0 kg de raízes tuberosas de mandioca imersas em água e a matéria seca (MS) destas raízes determinada com secagem em estufa, de quatro cultivares de mandioca, em que MS1 representa a matéria seca obtida por secagem em estufa das raízes colhidas de 14 a 22 meses após o plantio (MAP) e MS2 das colhidas de 10 a 13 MAP, com respectivos coeficientes de determinação $\left(R^{2}\right)$ e erro padrão da estimativa (Se). A linha pontilhada representa a equação de Grossman \& Freitas (1950) em que $y=15,75+0,0564 x$. Jaguaruna, SC, julho de 2016 a julho de 2017 Figure 3. Simple linear regression equations between the weight of $3.0 \mathrm{~kg}$ of waterimmersed cassava tuber roots and the dry matter (MS) of these roots determined by the oven drying method of four cassava cultivars, where MS1 represents the dry matter obtained by drying of the roots harvested 14 to 22 months after planting (MAP) and MS2 of the roots harvested from 10 to 13 MAP, with respective determination coefficients $\left(R^{2}\right)$ and estimate standard error (Se). The two equations in the graph presented the angular coefficients with statistical significance at the $1 \%$ probability level by the $t$-test. The dotted line represents the Grossman \& Freitas (1950) equation where $y=15.75+0.0564 x$. Jaguaruna, SC, Brazil, July 2016 to July 2017

teores de matéria seca determinados pelos dois métodos variou entre genótipos, anos, locais e ciclos fenológicos.

\section{Referências}

BREGAGNOLI, M. Qualidade e produtividade de cultivares de batata para indústria sob diferentes adubações. 2016. 141f. Tese (Agronomia) - Escola Superior de Agricultura "Luiz de Queiroz", Piracicaba, SP, 2006. Disponível em: https://teses.usp.br/teses/disponiveis/11/11136/tde-19052006-154403/ publico/MarceloBregagnoli.pdf. Acesso em 15 de setembro de 2019.

CARVALHO, P.R.N.; MEZZETTE, T.F.; VALLE, T.L.; CARVALHO, C.L.R.; FELTRAN, J.C. Avaliação da exatidão, precisão e robustez do método de análise do teor de matéria seca de mandioca (Manihot esculenta, Crantz) por meio da determinação do peso especí(Relatório PIBIC/CNPq, FCA, UNESP). do teor de matéria seca pelo peso específico em mandioca. Revista Agronômica, Porto Alegre, v.14, n.160/162, p.75-80, 1950.

MAEDA, M.; DIP, T.M. Curvas de porcentagem mássica de água versus peso específico em vegetais in natura - Otimização de processos industriais pela seleção via teste da matéria-prima. Ciênc. Tecnol. Aliment., Campinas, v.20, n.3, 2000. Disponível em: http:// www.scielo.br/scielo.php?pid=S0101$20612000000300006 \&$ script $=s c i$ abstract\&tlng=pt. Acesso em: 13 de agosto de 2019.

NUNES, E. da COSTA. Caracterização físicoquímica do amido e cultura de células e tecidos vegetais como ferramentas biotecnológicas à seleção e conservação de germoplasma de mandioca de mesa ( $M a$ nihot esculenta Crantz), 2013. 167p. Tese (Doutorado em Biotecnologia e Biociências) - Centro de Ciências Biológicas, Universidade Federal de Santa Catarina, Florianópolis, SC,2013.

OLIVEIRA, N.T. de; ALVES, J.M.A.; UCHÔA, S.C.P.; RODRIGUES, G.S.; MELVILLE, C.C.; ALBUQUERQUE, J.A.A. de. Caracterização e identificação de clones de mandioca produzidos em Roraima para o consumo in natura. Revista Agro@mbiente On-line, Boa Vista, v.5, n.3, p.188-193, 2011. Disponível em: https://revista.ufrr.br/agroambiente/ article/view/624. Acesso em: 30 de outubro de 2019.

POLA, A.C.; MORETO, A.L.; NUNES, E. C.; PERUCH, L.A.M.; NEUBERT, E.O. Variações na produtividade e matéria seca de raízes de mandioca em função da época de colheita. Agropecuária Catarinense, Florianópolis, v.30, n.3, p.79-83, 2017. Disponível em: http://publicacoes.epagri.sc.gov.br/index. php/RAC/article/view/149/149. Acesso em: 30 de outubro de 2019. todo de balança hidrostática na avaliação do teor de amido em duas cultivares de mandioca (Manihot esculenta Crantz). Botucatu: Centro de Raízes e Amidos Tropicais, Universidade Estadual Paulista, 1998. 14p.

GROSSMAN, J.; FREITAS, A.C. Determinação
WREGE, M.S.; STEINMETZ, S.; REISSER JUNIOR, C. ALMEIDA, I.R. de. Atlas climático da região sul do Brasil: estados do Paraná, Santa Catarina e Rio Grande do Sul. Pelotas: Embrapa Clima Temperado; Colombo: Embrapa Florestas, 2a ed., 2012, 333p. 